\title{
1968 E NÓS: crise de representação e movimentos sociais
}

\author{
Gabriel Pietro Siracusa *
}

\begin{abstract}
O artigo busca examinar o movimento conhecido como "coletes amarelos", ocorrido na França, em seus desenvolvimentos e principais reivindicações expostas até janeiro de 2019. Primeiramente, realiza-se uma discussão teórica acerca da crise da democracia representativa, buscando ligar o movimento que teve início em 2018 àqueles que ocorreram 50 anos atrás, em maio de 1968. Nesse sentido, procura-se estabelecer uma linha de continuidade entre movimentos que exigem uma real democratização do poder. Em segundo lugar, tenta-se destacar as possíveis contribuições do movimento dos coletes amarelos à uma concepção de ciência política e de democracia mais aberta e plural.
\end{abstract}

Palavras-chave: Democracia Representativa. Movimentos Sociais. Coletes Amarelos. Multidão. Momento Populista.

\section{INTRODUÇÃO}

Partimos de uma constatação: a democracia burguesa - liberal-representativa - encontra-se em crise. Por toda parte, vemos despontar movimentos questionando seus limites. Com ela, entram em crise também as teorias que lhe davam suporte. Em poucas palavras, estas costumam definir a democracia pelo binômio entre competitividade eleitoral (intra-elites) e participação política, na forma do direito ao voto. Não precisamos ir muito longe para constatar que ambas as proposições se encontram em apuros: de um lado, a cada eleição a aparência de disputa de ideias vem se dissipando e dando lugar ao que Michael Hardt e Antonio Negri chamaram de "extremismo centrista": a perspectiva segundo a qual uma política virtuosa é aquela que se move em direção ao centro, não deixando nenhum espaço para o conflito democrático de ideias. Segun-

* Universidade de São Paulo. Faculdade de Filosofia, Letras e Ciências Humanas. Departamento de Ciência Política.

Av. Prof. Luciano Gualberto, 315. Cep: 05508-900. São Paulo - São Paulo - Brasil. gabriel.siracusa@usp.br https://orcid.org/0000-0002-3120-6955 do os filósofos, “o ‘centro' imobiliza a política, não no sentido de ser ele mesmo imóvel, mas no de poder permanecer dominada pelo centro, toda transformação" (Hardt; Negri, 2018, p. 327). De outro lado e como conseqüência direta desse exacerbamento do centro político, temos o sentimento cada vez mais disseminado de que apenas o voto não basta. As pessoas querem participar mais e de outra forma da política. Como afirmam os indignados espanhóis: "tenemos voto, pero no tenemos voz". ${ }^{1}$

No entanto, se olharmos mais a fundo, veremos que a crise da democracia representativa tem raízes mais antigas. Talvez ela já tenha 50 anos. A linha do tempo é a seguinte: (i) em 1968, inúmeros movimentos tomam a palavra para questionar as estruturas e hierarquias vigentes; (ii) em resposta, temos a ascensão do neoliberalismo; (iii) desponta, então, um novo ciclo de lutas: primeiro as alter-mundialistas, que se iniciam em 1994 com o levante zapatista e vão até o onze de setembro, quando tem início a guerra ao terror; depois, na esteira da 1 https://www.theguardian.com/commentisfree/2018/dec/ 10/even-if-brexit-is-cancelled-it-wont-erase-the-divisions-of-the-last-two-years acesso em 12 de janeiro de 2019. 
crise de 2008, mas principalmente a partir de 2011, inúmeros movimentos de ocupação de praças e parques tomam as manchetes em todo o mundo; (iv) estes movimentos continuam ainda hoje, mas os poderes organizados já armam sua resposta, agora sob a forma do populismo de direita e de extrema-direita. Neste artigo, buscaremos analisar em linhas gerais esses quatro momentos. ${ }^{2}$

\section{A REVOLUÇÃO MUNDIAL DE MAIO DE 1968}

O ano de 1968 foi marcado por uma irrupção democrática radical. O princípio da desobediência se espalhou como uma epidemia, contagiando corações e mentes ao redor do mundo. "Uma combustão espontânea de espíritos rebeldes" como falou Mark Kurlansky (2005, p. 14). Uma revolução mundial, como disse Immanuel Wallerstein (1989). Em 1968, as pessoas rebelaram-se em torno de questões distintas, porém foram mobilizadas por um desejo em comum de se revoltar contra qualquer forma de autoritarismo e de hierarquias. Foram rejeitados os líderes políticos, seus partidos e suas instituições (Kurlansky, 2005, p. 13-14). Uma desobediência viral. Não se lutou apenas por melhores condições de vida, mas também por outras formas de vida.

Não existe uma imagem unificada e côจิ moda para 1968. Na França, por exemplo, as ปิ ocupações da Sorbonne, da fábrica da Renaultปู -Billancourt e do teatro Odeón retratam a mul\& tiplicidade de lutas que despontaram naquele $\underset{I}{+}$ ano. A juventude - tanto operária, quanto estu¿. dantil - marcou presença forte. As ocupações ळ de fábrica em geral eram iniciadas por jovens

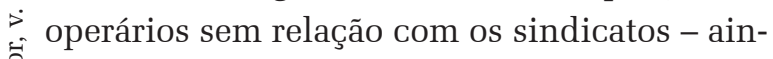
da que estes se somassem à luta, após a fagulha inicial. Outra marca forte do movimento de

承 ${ }^{2}$ Vale ressaltar que a análise do artigo, escrito no início de 2019, não avança nos acontecimentos e desdobramentos ocorridos após esta data. Por limites de espaço, não será possível discutir e atualizar os desdobramentos dos movimentos de rua e das disputas político-eleitorais que ocorreram desde então.
1968 foi o surgimento das lutas por libertação nacional - no Vietnã e na Palestina em especial - e a solidariedade que estas geraram ao redor do mundo. A luta anti-colonialista tocava o coração das pessoas no mundo inteiro.

Na Alemanha, na França, nos EUA, no México, no Brasil, por toda parte os estudantes foram às ruas para reivindicar uma educação libertadora, liberdade sexual, igualdade de gênero, direitos reprodutivos. Nos EUA, em especial, o movimento pelos direitos civis teve momentos marcantes. No âmbito do movimento operário, greves selvagens ${ }^{3}$ despontaram e as ocupações de fábrica se generalizaram. A maior greve geral de toda a história francesa (Badiou, 2012 [2009], p. 31): em um país com 50 milhões de habitantes, 10 milhões entraram em greve (Tible, 2018; Negri, 2018). ${ }^{4}$

Como coloca Badiou (2012 [2009], p. 38), 1968 foi isto: "o conjunto de experiências que mostrou como a impossível reviravolta dos lugares sociais era politicamente possível, por intermédio de um tipo inédito de tomada de palavra, e da busca hesitante de formas de organização adequadas à novidade do acontecimento". Se podemos encontrar uma marca que unifique 1968 é a insubordinação e a desobediência: movimentos anti-autoritários, ausência de lideranças ou líderes que negavam sê-lo, recusa às hierarquias, etc. "Essa crise é produzida não só pelas demandas por melhores salários e melhores condições de vida dos trabalhadores, mas também por uma insubordinação generalizada, articulada com outros movimentos e demandas" (Tible, 2018, p. 14).

Nesse sentido, a democracia representativa foi um alvo privilegiado: "houve enfim, e talvez sobretudo, uma crítica radical da demo-

${ }^{3}$ Greves selvagens, termo que se refere às mobilizações iniciadas e/ou levadas adiante espontaneamente, pelos trabalhadores, sem a participação ou à revelia do sindicato.

${ }^{4}$ Não cabe, nos limites deste artigo, discorrer longamente acerca das relacões entre o movimento operário e o movimento estudantil de maio de 68 francês. Para mais informações, inclusive, a respeito do lugar dos trabalhadores intelectuais ou de intelectuais proletarizados, remetemos à análise de Michael Löwy em "Algumas hipóteses sobre a radicalização dos intelectuais" (Löwy, 1998 [1979], p. 259-284). 
cracia representativa, do quadro parlamentar e eleitoral, da 'democracia' em seu sentido institucional, constitucional”. A desconfiança com a política institucional não era casual: "depois de um mês de uma mobilização estudantil, operária e popular sem precedentes, o governo conseguiu organizar eleições e o resultado foi a Câmara mais reacionária que já se viu!” (Badiou, 2012 [2009], p. 35-36). De maneira similar, após junho de 2013, elegeu-se no Brasil o congresso mais conservador desde $1964 .{ }^{5}$

O dispositivo eleitoral não era visto apenas como um dispositivo de representação, mas, ao mesmo tempo, como um dispositivo de repressão, de manutenção da ordem. Talvez, não por acaso, em 1973 Sartre sintetiza este sentimento em famoso artigo na revista Les Temps Modernes ${ }^{6}$ : "Élections, piège à cons" ("Eleições, armadilha para ingênuos", em tradução livre) - uma das palavras de ordem mais simbólicas de 1968. Nos muros, lia-se: "voter, c'est abdiquer" ("votar, é abdicar", em tradução livre). De fato, com 1968 assistimos ao possível fim de uma determinada concepção de política, ao questionamento radical das instituições tradicionais, inclusive, às organizações históricas da esquerda, sindicatos, partidos etc.

Buscava-se, então, uma visão nova da política. Uma prática da política que não aceitava deixar as coisas em seu lugar, "que aceitava trajetos inéditos, encontros impossíveis, reuniões entre pessoas que comumente não se falavam” (Badiou, 2012 [2009], p. 38). Não se tratava mais de organizar cada um em seu lugar: o estudante na universidade, o operário na fábrica, mas organizar deslocamentos, agenciar encontros. Operários, jovens e intelectuais juntos, sem mediação das direções dos organismos tradicionais. A partir de então,

5 https://politica.estadao.com.br/noticias/eleicoes, congresso-eleito-e-o-mais-conservador-desde-1964afirma-diap,1572528 acesso em 14 de janeiro de 2019 . Importante destacar que o paralelo entre os dois momentos se limita a ressaltar o descompasso entre as forças em ebulição na sociedade e o resultado eleitoral.

${ }^{6}$ Revista fundada por Jean Paul Sartre e Simone de Beauvoir no pós $2^{\text {a }}$ Guerra. Para mais informações, cf. https:// web.archive.org/web/20071009103137/http://www.gallimard.fr/web/gallimard/catalog/Html/revue/temp.htm formou-se um amplo debate sobre a crise da representação, dos partidos e da democracia liberal representativa em geral. A explosão democrática de 68 colocou em cheque os pressupostos teóricos e práticos vigentes até então e foi lida pelos teóricos da ordem como um excesso de democracia (Huntington, 1976).

De fato, os intelectuais da ordem sempre insistem que não há alternativa. Fazem agora como o fizeram em 1968. Porém, a despeito desta insistência, 1968 confirma o pressuposto de que o mundo, tal como ele é, não é necessário. Passa-se, então, da não-necessidade à possibilidade: outro mundo é possível e 1968 escancarou isso. Tal consciência, porém, desperta reações ferozes: depois de tamanho terremoto, o antigo estado de coisas não poderia ressurgir como se nada tivesse acontecido. O mundo mudou para sempre (Badiou, 2012 [2009], p. 19), mas os poderes estabelecidos tentam reestabelecer a ordem. Como argumenta Tible (2018, p. 14), “1968 marca o início do nosso mundo contemporâneo. Uma fenda no sistema de domínio, que provocou uma reação profunda, tanto política quanto econômica”.

\section{MOMENTO DE TRANSIÇÃO PÓS- 1968: a formação da hegemonia neoliberal}

Podemos compreender o período pós1968 como um interregno: uma transição, cuja direção ainda está em disputa, mas que foi hegemonizada por quase 30 anos pelo que se convencionou chamar de neoliberalismo: uma conjunção espúria entre o Estado mínimo, em termos econômicos e sociais e, máximo em termos de repressão e controle. Nesta seção, procuramos esboçar em linhas gerais como se deu a reação aos movimentos de 1968.

Costuma-se afirmar que 1968 se prolongou por quase dez anos. Na década de 1970 testemunharam-se inúmeras lutas que se estenderam até o seu final, quando finalmente o 
neoliberalismo se impôs enquanto sistema de ideias, de organização das estruturas sociais de produção e das formas sociais de trabalho; como resposta, enfim, à irrupção democrática de 1968 um conjunto de ideias que, de certa forma, jogou a pá de cal sobre os últimos vestígios da democracia representativa-liberal, a qual continua a existir apenas como um semi-morto que insiste em não ser enterrado.

No fim daquela década, vimos ruir o consenso do pós-guerra que havia sido estabelecido - em especial na Europa e nos Estados Unidos - em torno do Estado de Bem-Estar Social keynesiano:

O desacoplamento do dólar com relação ao padrão ouro em 1971 e a crise do petróleo de 1973 marcam as datas de início do fim de uma época que, no Ocidente, foi celebrada como os "30 anos gloriosos" - a época do 'fordismo' e da complexa geopolítica de conflitos, guerras frias e quentes, revoluções, insurgência e contra-insurgência que a acompanhou em escala mundial (Gago; Mezzadra, 2015, p. 38).

Existem inúmeras datas que marcam a progressiva ascensão neoliberal, que se deu tanto por meio do que Naomi Klein (2008 [2007]) chamou de "Doutrina do choque", quanto por meio de programas de ajuste ditados por organismos financeiros internacionais. De uma maneira geral, o golpe militar no Chile de Allende em 1973 e o início dos governos Thatcher, Inglaterra (1979) e Reagan, EUA (1981), são normalmente lembrados para desจิ crever como tudo começou.

ง $\quad$ O que é, exatamente, o neoliberalismo? Trata-se de um fenômeno global, mas que assume formas variadas, a depender da região para onde olhamos (Brown, 2015, p. 20). De ¿. uma maneira geral, pode-se dizer que se traले ta de um novo paradigma de organização das $\vec{*}$ estruturas sociais de produção e das relações entre o público e o privado. Pode ser lido ao mesmo tempo como um conjunto de políticas econômicas a ser adotado e como uma nova subjetividade, baseada no individualismo e na competição, uma nova racionalidade que orga- niza e orienta tanto as condutas empresariais e estatais, quanto as individuais, estendendo o modelo do mercado para todos os âmbitos da vida (Brown, 2015, p. 31).

Tratemos, primeiramente, das políticas econômicas propugnadas pelo neoliberalismo. Em geral, o objetivo dessas políticas era "reorganizar a produção em direção à acumulação de riqueza e à extração do comum visando fins privados" (Hardt; Negri, 2018, p. xviii). Dentre as principais ideias norteadoras, destacam-se noções como: austeridade fiscal, reforma tributária regressiva, privatização de bens públicos, desregulamentação da exploração privada de recursos naturais, privatização de serviços públicos essenciais (como sistemas de seguridade social, de saúde, educação, etc.), liberalização comercial e financeira, dentre outras cujo princípio básico é afirmar o livre mercado (Brown, 2015, p. 28). Em geral, um dos principais efeitos das reestruturações neoliberais sobre as economias nacionais foi o aumento vertiginoso da concentração de renda nas mãos do $1 \%$ mais ricos da população.

A despeito disso, o instrumental econômico neoliberal foi progressivamente se impondo como única alternativa possível à diminuição do crescimento, ao aumento da inflação e à crise fiscal pelos quais passavam a maior parte dos Estados nacionais nos anos 1980. Neste contexto, as forças socialdemocratas não conseguiram se opor ao ataque desferido contra o modelo keynesiano e foram derrotadas, cultural e ideologicamente, pelo projeto neoliberal, aceitando o terreno hegemônico estabelecido pelo neoliberalismo em praticamente todo o Ocidente (Mouffe, 2018). Com a queda do muro de Berlim, em 1989, esta ausência de alternativas é teorizada sob a forma do "fim da história" (Fukuyama, 1989).

Neste contexto, forças socialdemocratas até então identificadas com a esquerda acabaram implementando o receituário neoliberal, no que se convencionou chamar de social-liberalismo, ou, mais recentemente, neolibera- 
lismo progressista. $^{7} \mathrm{Na}$ época, tal fenômeno foi teorizado como uma terceira via, "nem de esquerda, nem de direita", e teve forte impacto nos EUA (Bill Clinton) e na Grã-Bretanha (Tony Blair) ${ }^{8}$. Forma-se uma espécie de consenso "de centro”, caracterizado por Hardt e Negri (2018) como "extremismo centrista" e por Chantal Mouffe (2018) de "ilusão do consenso". Trata-se de uma situação objetivamente "pós-política” e, inclusive, "pós-democrática”, ${ }^{9}$ mesmo nos termos mínimos do governo representativo: os cidadãos viram-se privados da possibilidade de optar entre diferentes projetos de sociedade e, assim, exercer seus direitos democráticos. Na noite neoliberal, a democracia viu-se reduzida a uma legitimação periódica, por meio do voto, de algum gato pardo, indiferenciado, no essencial, de seu concorrente. Ganha fôlego uma forma tecnocrática, segundo a qual a política não seria um conflito entre opiniões divergentes, mas uma gestão neutra e tecnicamente embasada dos assuntos públicos. ${ }^{10}$ Cada vez mais, os políticos procuram se apresentar como "gestores", tentando esconder seu passado político. ${ }^{11}$

Diante dessa indistinção, as pessoas começaram a se questionar por que ir votar? Tratou-se de um movimento de fundo comum a toda a Europa Ocidental - e, virtualmente,

7 https://www.brasildefato.com.br/2017/01/27/o-fim-do-neoliberalismo-progressista/

${ }^{8}$ Mas não só. Como lembra Alain Badiou, na França, a partir de 1982-1983 vemos "uma liberalização financeira sem precedentes, que foi concebida por Bérégovoy e iniciou a inclusão da França no capitalismo globalizado mais feroz" (Badiou, 2012 [2009], p. 38-39).

${ }^{9}$ Os termos pós-política e pós-democracia fazem referência a uma situação em que o fazer político é posto de lado em detrimento a uma perspectiva técnica, quando, supostamente, não haveria alternativas a seguir, a não ser aquela determinada pelo especialista - normalmente, o economista ou o jurista. No entanto, é importante ressaltar que a negação da política assume diferentes formas a depender do contexto sócio-histórico específico, indo além do escopo deste texto discutir mais a fundo a questão.

${ }^{10}$ É preciso ressaltar, como lembra Mouffe (2018), que a forma utilizada por políticos neoliberais já havia sido mobilizada para a implementação do Estado de bem-estar: de cima para baixo, sem participação popular, com um discurso tecnocrático, etc. Ironicamente, Mouffe apresenta argumentos contrários a seu próprio projeto político de retorno às formas democráticas pré-neoliberalismo.

11 https:/epoca.globo.com/politica/noticia/2017/04/joao-doria-eu-nao-sou-politico-nao.html a todo o Ocidente. As pessoas querem ser escutadas, querem ter voz, participar. Diante da ausência de alternativas programáticas reais, votar perde sentido e as taxas de absenteísmo aumentam assustadoramente, somadas à queda na identificação partidária. Nos termos já citados, na pós-política limita-se a uma alternância entre forças de centro-direita e de centro-esquerda que, na prática, implementam o mesmo programa: os ditames do capitalismo financeiro neoliberal. O poder do povo, um dos pilares do ideal democrático, foi minado, uma vez que a pós-política elimina a possibilidade de uma luta agonística entre diferentes projetos de sociedade, o que é a própria condição para o exercício da soberania popular. Neste ponto, identificamos a proposta de Chantal Mouffe, exposta especialmente em seu livro Por um populismo de esquerda (2018).

Em linhas gerais, trata-se de buscar reativar o caráter agonístico da democracia, traçando uma linha divisória entre o povo e as elites, um "nós" e um "eles". Com isso, espera-se recuperar as bases democráticas para, após, radicalizá-las. Conforme exploraremos mais adiante, esta estratégia está na base de vários movimentos contemporâneos de disputa eleitoral, como o "Podemos" na Espanha, o "Syriza” na Grécia, o "die Linke" na Alemanha, o "Bloco de Esquerda" em Portugal e o "La France Insoumise” na França. Na Grã-Bretanha, apresenta-se um movimento, liderado por Jeremy Corbyn, de reorganização dentro do partido trabalhista, que compartilha de forma geral essas ideias. Nos EUA, o mesmo esforço materializou-se na figura de Bernie Sanders e dos socialistas democráticos.

Porém, o neoliberalismo mina a democracia representativa liberal de uma forma ainda mais profunda. Como mencionamos anteriormente, além de um conjunto de políticas econômicas a serem adotadas pelo Estado, o neoliberalismo é também uma nova forma de razão. Trata-se de uma formulação levada a cabo, no campo da teoria política, por autoras como Wendy Brown que, partindo das formu- 
lações de Foucault do final da década de 1970, definirão o neoliberalismo como uma "ordem normativa da razão” (Brown, 2015, p. 9), uma racionalidade política nova, permeada por formas econômicas, que é fruto de um processo de subjetivação inédito. As práticas agora impulsionadas e obtidas dos indivíduos, assim como os discursos mobilizados a respeito destes indivíduos, da sociedade e do Estado, tendem a generalizar este novo processo de subjetivação, cujos resultados, para o exercício da democracia, são absolutamente catastróficos.

Como apontou Brown, trata-se de uma "economização" de todas as esferas da vida do sujeito político contemporâneo, isto é, uma efetiva redução de todas as atividades humanas à estrita gramática econômica - a formação do homo economicus neoliberal (Brown, 2015, p. 31). Ocorre, aqui, um deslocamento fundamental no que diz respeito às ações propriamente políticas dos indivíduos e dos corpos sociais. Compreendido como um capital de si, seguindo o modelo empresarial, o sujeito busca incessantemente formas de maximizar seu valor presente, "investindo em si" e construindo um valor futuro maior para si próprio (Brown, 2015, p. 22). Assim, a figura do indivíduo vai se afastando daquela do cidadão portador de direitos e se aproximando, cada vez mais, da figura dupla do consumidor/empreendedor, emulando uma empresa capitalista. Neste contexto, ações como o exercício ou a จิ reivindicação de direitos, outrora compreenป didas como eminentemente políticas, passam a ser compreendidas como ações econômicas, regidas por uma racionalidade tipicamente fi empresarial: o sujeito, como um consumidor $\dot{2}$ de políticas a serem providas por um Estado 今 visto, ele também, como uma empresa. O su-

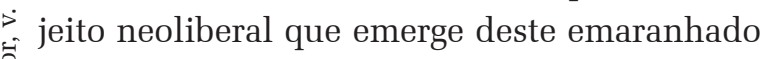
de práticas e discursos carece, portanto, de características indispensáveis ao funcionamento do governo representativo.

No entanto, um novo ciclo de lutas veio perturbar a aparente calmaria do oceano neoliberal. O discurso e a prática neoliberais, a des- peito de seu aspecto totalizante, deixam muitas brechas para resistência; o poder é sempre uma relação de forças e é preciso apreendê-lo de acordo. Primeiro em Chiapas, em 1994, e depois com as inúmeras manifestações que acompanharam as reuniões dos organismos financeiros internacionais podemos observar o que Michael Hardt e Antonio Negri (2018) descrevem como o surgimento de movimentos multitudinários. Este ciclo específico de lutas se estende até 2001, quando perde força diante da guerra ao terror, embora permaneça organizado, anualmente, na forma do Fórum Social Mundial, à procura de uma alternativa contra a globalização neoliberal e por um aprofundamento da democracia.

Em 2008, a crise. Iniciada em 2007, com o colapso do mercado de subprimes, ela se espalha por todo o sistema bancário internacional. Seu conteúdo real é uma crise de moradia, o que indica que a precarização gerada pelas políticas neoliberais atingiu seu auge. Os Estados nacionais são então mobilizados para despejar dinheiro nas instituições financeiras à beira da falência. Como consequência lógica, segue-se uma crise fiscal profunda, em grandes extensões do globo. Este momento de crise é ainda o atual. Veremos em mais detalhes, na próxima seção, quais as alternativas que se colocam à hegemonia neoliberal, após a crise de 2008. Os movimentos que daí surgiram reabrem a questão a respeito da direção da transição pós-1968 (Gago; Mezzadra, 2015, p. 39). A história, afinal, não tinha, de fato, acabado. Os movimentos de 2011 aparecem em cena, trazendo consigo as ocupações de praças parques, grandes marchas, por vezes violentas, questionando regimes pouco democráticos - na África do Norte, mas também na Europa e nos EUA.

Movimentos que reivindicam melhores condições de vida e uma "democracia real", marcados por horizontalidade e por uma profunda desconfiança diante das instituições tradicionais, tanto as do governo representativo, quanto as da "esquerda tradicional". São múltiplas experiências que prefiguram em ato uma 
política de natureza diferente, distante do poder do Estado, procurando criar regimes mais democráticos de convivência e de partilha do comum. Seguiremos a análise proposta por Hardt e Negri em seu livro Assembly (2018), por considerarmos o instrumental teórico proposto por estes autores, mais completo e potente do que aquele apresentado, por exemplo, por Chantal Mouffe em obra já mencionada. Por fim, analisaremos brevemente o movimento dos "gilets jaunes", visto como um exemplo de movimento multitudinário que demanda em especial uma nova forma de democracia, que os autores teorizam como autogoverno da multidão.

\section{DOS MOVIMENTOS DE 2011 ÀS REVOLTAS DO PRECARIADO}

Em um artigo publicado em 2018, o antropólogo estadunidense David Graeber afirmou que vivemos tempos revolucionários (Graeber, 2018). De fato, a partir de 2011 teve início um ciclo de lutas em escala global que marcou a segunda década de nosso século de forma indelével. Estes movimentos trazem consigo traços de lutas anteriores: desde as lutas de 1968, passando pelo levante zapatista de 1994 e pelas lutas altermundialistas do fim do século passado chegando até nós. São movimentos sem liderança definida, marcados por uma profunda horizontalidade, pela democracia participativa e por um repúdio à hierarquia. "Esses movimentos provaram-se aptos a exortar ideais democráticos, a ocasionalmente forçar a implementação de reformas e a pressionar, ou mesmo derrubar regimes" (Hardt; Negri, 2018, p. 5). Estes autores, porém, não deixam de observar que, em geral, esses movimentos tendem a ter vida curta. Nascem de forma espontânea e contagiosa, sem planejamento centralizado e muitas vezes sem organização e logo desaparecem. São como um grito "de basta”, em virtude da precarização sem fim, promovida pelo neoliberalismo. Ocorrem como motins, como ocupações, como ação di- reta (Pinheiro-Machado, 2018), mas não têm vida longa.

Normalmente, organizam-se em torno de pautas concretas do cotidiano: o preço das tarifas de ônibus, nas jornadas de junho no Brasil, (Pinheiro-Machado, 2018), ou a falta de moradia na Espanha, a violência policial em 2016 e o preço do diesel, no ano passado, na França, etc. Por vezes, crescem e viralizam, evoluindo para pautas maiores: o custo de vida, a corrupção, a desigualdade social, os limites da democracia representativa. Até agora, porém, eles têm seguido roteiro familiar: "tomam brevemente as manchetes ao redor do globo e, então, aos poucos, somem de vista" (Hardt; Negri, 2018, p. xiii). Para os dois filósofos, trata-se de um problema de organização, pois, "formas organizacionais modernas foram destruídas, e substitutos adequados ainda não foram inventados" (Hardt; Negri, 2018, p. 12):

[...] ativistas têm criticado, com razão, a forma como modos de organização centralizados e verticais, que incluem figuras carismáticas, conselhos de liderança, estruturas partidárias e instituições burocráticas, tornaram-se grilhões para o desenvolvimento da democracia e para a participação plena de todos na vida política. (Hardt; Negri, 2018, p. xiv).

Não se deve, no entanto, recusar in toto as instituições, "banir a verticalidade apenas para fazer da horizontalidade um fetiche e ignorar a necessidade de estruturas sociais duráveis", mas "organizar a produção de subjetividade necessária para criar relações sociais duradouras" (Hardt; Negri, 2018, p. xiv). Trata-se de recusar tanto o fascínio dos poderes estabelecidos, quanto a "tentação sacrificial do nada", isto é, de proceder à sua "destruição infecunda” (Badiou, 2012 [2009], p. 16; 22). Assim, duas tarefas se impõem aos movimentos hodiernos: construir organizações sem hierarquia e criar instituições sem centralização.

Nesse sentido, Hardt e Negri não propõem uma recusa da liderança, mas uma inversão da relação política que normalmente liga movimentos horizontais e liderança vertical. 
Consubstanciada na formulação "estratégia aos movimentos e tática à liderança” (Hardt; Negri, 2018, p. 28), os filósofos defendem que as decisões estratégicas de longo prazo devem ser tomadas democraticamente pela multidão, ficando os líderes responsáveis por questões táticas imediatas. Trata-se, assim, de um novo tipo de organização: "a serviço dos movimentos e a eles subordinado" (Hardt; Negri, 2018, p. 29).

Podemos pensar esta questão como uma característica prefigurativa, na qual o movimento põe em prática aquilo que quer construir na sociedade: em diversos movimentos que fazem da democracia e do anti-autoritarismo seus fundamentos, a participação é "fomentada como antídoto à representação, e a democracia participativa como alternativa à liderança centralizada" (Hardt; Negri, 2018, p. 15). ${ }^{12}$ Neste sentido, a multidão estaria se preparando para, de fato, ser capaz de tomar decisões concernentes à sociedade como um todo; ficando aos líderes a responsabilidade de resolver questões táticas imediatas, isto é, seu "funcionamento deve ser limitado a julgamentos táticos concernentes à forma de aplicação da estratégia social geral durante circunstâncias em mutação, devendo a liderança ser completamente subordinada à multidão e nela submergida" (Hardt; Negri, 2018, p. 29). Mandar obedecendo; uma liderança clastriana.

É neste sentido que os autores valorizam experiências como o Syriza e o Podemos: จิ partidos que se valem, "experimentalmente, i de novas relações entre elementos verticais ธิ e horizontais" (Hardt; Negri, 2018, p. 29). No ¿ entanto, Negri e Hardt alertam contra o periI go populista, isto é, contra o risco de que tais ¿ formações políticas se separem de tal modo ले de sua origem no movimento social, superestimando a importância do poder estatal e, de certo modo, desvalorizando o papel político dos movimentos sociais em seu interior. Seguindo por esse caminho, essas novas expe-

${ }^{12}$ Como por exemplo as tentativas feitas pelo Black Lives Matter de combinar organização democrática com eficácia política. Cf. Hardt; Negri, 2018, p. 16-18. riências estariam mantendo a estratégia nas mãos da liderança e a tática aos movimentos (Hardt; Negri, 2018, p. 33-34). De certa forma, foi o que observamos com grande parte das experiências de partidos de esquerda no último ciclo latino-americano.

Uma forma de escapar a essa separação seria negar, na prática, a autonomia do político. Este seria uma das características mais marcantes do último ciclo de mobilizações:

[...] no poderoso ciclo de movimentos sociais que se desenvolveu a partir de 2011, muitos desses elementos não somente reaparecem, mas foram desenvolvidos e aprofundados na subordinação de noções relativas à autonomia do político a projetos que entretecem liberação política, econômica e social; na redefinição do poder constituinte como um processo contínuo de transformação; e na promoção e constitucionalização de uma pluralidade de subjetividades sociais diversas. (Hardt; Negri, 2018, p. 51)

Isto pode ser observado na forma como muitos desses movimentos entretecem o político, o econômico e o social, associando demandas por mais democracia - ou por uma "democracia real" - à luta por melhores condições de vida. Os acampamentos urbanos que se espalharam pelo mundo a partir de 2011 (praça Tahrir, Syntagma, Puerta del Sol, Ogawa, os parques Zucotti e TaksimGezi, a Cinelândia e o Vale do Anhangabaú) permitiram uma conversão temporária do espaço urbano em espaço comum, caracterizados pelo acesso aberto e por uma gestão democrática e participativa de todos os âmbitos da vida. Ademais, os acampamentos demonstraram sua importância de outro ponto de vista: ao inverterem o abandono e a opacidade individualistas da rotina de trabalho precarizado imposta pelo neoliberalismo, mostraram, concretamente, novas práticas de cuidado, novas formas de vida coletiva, novos laços sociais sendo formados.

Vejamos como isso se materializa na mais recente manifestação desse ciclo de lutas: os gilets jaunes, na França. 
"O que nós estamos assistindo é sem precedentes na história francesa" 13

Em 08 de dezembro de 2018, uma imagem benjaminiana: manifestantes portando o colete amarelo que os identificava, iam se agrupando próximos ao Arco do Triunfo, trazendo consigo uma bandeira francesa com uma data em cada uma das cores: 1789, 1968 e 2018. O fato de os manifestantes se enxergarem como continuidade de 68 não é fortuito e não pode ser ignorado. Nesse sentido, o movimento dos gilets jaunes talvez seja o que melhor expressa as "temporalidades plurais do poder constituinte", pois, indica "tanto o poder de ações futuras quanto o potencial acumulado do passado" (Hardt; Negri, 2018, p. 52). Futuras, porque ainda que a repressão seja eventualmente bem-sucedida - o que ainda não está dado, pelo contrário ${ }^{14}$-, seus efeitos persistirão. Do passado, visto que demonstram trazer o acúmulo de lutas anteriores, tanto das mais recentes (Nuit Debout, ciclo de 2011), quanto das mais antigas (1968).

O movimento dos "coletes amarelos" começou como uma reação ao aprofundamento das políticas neoliberais postas em prática por Emmanuel Macron, o governante dos ricos. ${ }^{15}$ A retirada do ISF (Impôt de solidarité sur la fortune, imposto francês sobre as grandes fortunas) combinada com o aumento no preço do diesel serviu de fagulha para a multidão ir às ruas, desde 17 de novembro de 2018, todos os sábados, até o ano seguinte (o sábado, dia 19 de janeiro registrou novos protestos). Muitos já os têm caracterizado como uma revolta popular ou mesmo uma insurreição (Negri, 2018). Ainda é cedo para dizer qual caminho o movimento seguirá. A tentação do populismo de direita permanece à espreita, como no resto do

${ }^{13}$ https://roarmag.org/essays/gilets-jaunes-blown-old-political-categories/

${ }^{14} \mathrm{O}$ artigo foi originalmente escrito no início 2019.

15 http://www.le-chiffon-rouge-morlaix.fr/2016/07/emmanuel-macron-le-candidat-de-l-oligarchie-par-laurent-mauduit-mediapart-11-juillet-2016-habille-pour-l-ete-le-chouchou-de-la-finan mundo. Há, porém, elementos para sustentar que os gilets jaunes caminharão por outras avenidas.

\section{"On veut vivre, pas survivre"16}

Diante da amplitude dos protestos, o governo suspendeu e, mais tarde, revogou a elevação do tributo, sem se dar conta que, àquela altura, as reivindicações já eram outras: a precariedade dos serviços públicos no interior, a depreciação do poder aquisitivo, poucas perspectivas de futuro, a falta de interlocução do establishment político com os eleitores. De certa forma, suas demandas expõem o recorte de classe do movimento (Dardot; Laval, 2018), formado em sua maioria por assalariados e que, portanto, tenta re-valorizar o trabalho (Negri, 2019). Cerca de dois terços da população aprova o movimento (Negri, 2018), embora alguns cheguem a falar em $80 \%$ de apoio. ${ }^{17}$ O governo, cuja aprovação não chega a $20 \%,{ }^{18}$ tenta responder: aumento do valor do salário mínimo, diminuição de impostos para uma parte das aposentadorias e elaboração de um "grande debate nacional" - dois meses de consultas públicas sobre os mais variados temas. ${ }^{19}$

O significado social do movimento está posto de maneira clara e ele conseguiu colocar no centro do debate a questão da justiça social - algo que a esquerda tradicional havia abandonado. Uma multidão "composta por indivíduos de diferentes classes, de diferentes idades, de diferentes opiniões" (Dardot; Laval, 2018, online), que está se levantando com violência contra a miséria trazida pelas reformas neoliberais. Uma multidão que protesta contra

${ }^{16}$ Uma das frases pichadas nos coletes: "queremos viver, não sobreviver”, em tradução livre.

17 https://www.liberation.fr/debats/2018/12/21/gilets-jaunes-le-ric-comme-revendication-numero-1_1699252

18 https://roarmag.org/essays/gilets-jaunes-blown-old-political-categories/

19 https://www1.folha.uol.com.br/mundo/2019/01/macron-abre-debate-nacional-enquanto-coletes-amarelos-ganham-novo-folego.shtml?loggedpaywall 
a redução da força de trabalho à condição de precariado e contra as limitações impostas à vida pela insuficiência dos serviços públicos. É um levantar-se contra a miséria e contra "as escolhas feitas pelo banqueiro Macron a favor das classes dominantes" (Negri, 2018) - não por acaso, um dos cantos mais entoados durante os protestos é “Macron, démission!”. Eles trazem uma face desesperada (Negri, 2018), de quem vê suas condições de vida piorar cada vez mais, sem parecer ter como expressar seu descontentamento.

Neste sentido, como argumentam Dardot e Laval, abrem-se dois caminhos para o movimento: por um lado, a via nacionalista, protecionista, hiper-autoritária e antiecológica, seguida por Trump, Bannon, Salvini, Le Pen, Bolsonaro, Orban, etc. O populismo de direita, que visa se apresentar como uma alternativa às frustrações e aos ressentimentos provocados pelo aprofundamento das políticas neoliberais em todo o mundo, mas que nada mais é do que uma resposta dos poderes da ordem ao ciclo de lutas iniciado em 2011. Por outro lado, existe o "caminho democrático, ecológico e igualitário, que se afirmou há décadas em todas as lutas sociais e de resistência ao neoliberalismo, no movimento de justiça global, no movimento das praças, em muitos laboratórios do comum [...]" (Dardot; Laval, 2018, online).

Felizmente, ao que tudo indica, o movimento tem trilhado por este caminho, ainda จิ que não sem contradições e complexidades. กิ Afirma-se isto, tendo por base a constatação ปै de que os dois principais eixos de reivindica¿े ção que se consolidaram são: diminuição da $\underset{\text { I }}{ }$ desigualdade social e luta por uma "democracia real”. Isto é, está se desenhando uma clara œ aliança entre demandas políticas, sociais e eco-

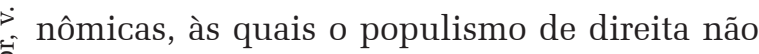
tem respostas. Nesse sentido, os gilets jaunes são um sintoma da profunda crise de legitimação pela qual passa o establishment político.

O centro neoliberal está em franca implosão, mas ainda não foram inventadas novas formas institucionais e organizativas. Ainda assim, a recusa do movimento - ao menos de parte dele - em seguir os caminhos tradicionais tem que ser vista com olhos auspiciosos. A proposta do RIC, ${ }^{20}$ que visa de certa forma coagular todas as demandas sociais anteriormente apresentadas e propor uma solução para todas elas, vai neste sentido, de recusar as intermediações e retomar o poder para a multidão (Negri, 2018). O movimento compreendeu que a democracia representativa gera uma rachadura radical na sociedade: aqueles que exercem o poder e aqueles sobre os quais ele é exercido (Onfray, 2018).

Os gilets jaunes recusam a representação e a intermediação - tanto da direita, quanto da esquerda. Ambos - la France Insoumise e o Rassemblement National - tentam se apropriar desta energia, canalizando-a para o caminho parlamentar, até agora sem obter sucesso. Desagradando teóricos do populismo, o movimento recusa líderes que o encarnem. Esta negação da representação é apresentada na mídia e por intelectuais como uma "falta", uma "incapacidade”. Poderíamos, porém, ler de modo diferente. O que para alguns é falta, para outros pode ser virtude. Justamente esta recusa de se fazer representar pode ser lida como a característica mais marcante do movimento, sua "recusa, em princípio, de qualquer representação" (Dardot; Laval, 2018, online). Como vimos ao longo deste artigo, tal recusa é plenamente justificada, em função da profunda crise de legitimidade pela qual passam governos, políticos tradicionais, a grande mídia, etc. A radicalização centrista neoliberal apenas exacerbou este processo, porém, ele parece que já tem, pelo menos 50 anos. Aliás, os 50 anos que separam as duas irrupções democráticas, uma em um momento de auge do consenso pós-guerra e de suposta estabilidade material e outra, num momento de crise global do capitalismo, mostram que o mal-estar perdura e é mais profundo do que querem nos fazer crer os intelectuais da ordem.

${ }^{20}$ Referendo de Iniciativa Cidadão. Para mais informações, cf. https://samuelhayat.wordpress.com/2018/12/24/les-gilets-jaunes-et-la-question-democratique/ 
Porém, existe ainda algo mais fascinante na recusa da representação que os gilets jaunes apresentam. Trata-se de sua contrapartida positiva, de sua capacidade instituinte, que tem passado ao largo da maior parte das análises, mas que não pode ser ignorada. Os sujeitos que foram às ruas ao longo de dois meses acreditam "em sua própria força coletiva para se fazer ouvir e para formular suas reivindicações, [...] a partir das condições insuportáveis vividas por indivíduos reais e até então invisíveis" (Dardot; Laval, 2018, online). E o fazem por meio da auto-organização de ações de rua, de barreiras e barricadas, de bloqueios e acampamentos nas estradas, de grandes manifestações de rua. E o fazem ainda em reuniões e assembleias em que as reivindicações coletivas são formuladas. Neste sentido, vemos como os movimentos vão sedimentando suas experiências, aprendendo uns com os outros. O apelo do movimento é por uma política insurrecional, realmente democrática e ele parece trabalhar com o novo senso comum democrático de que nos fala Graeber (2018). O chamado dos gilets jaunes de Commercy é exemplar neste sentido e parece demonstrar claramente o espírito de democracia direta que anima os Comitês de Base do movimento:

[...] O sofrimento, a frustração e a injustiça nunca foram tão generalizados. Agora, por todo o país, centenas de grupos locais se organizam entre si, com maneiras distintas de funcionamento.

Aqui em Commercy, em Meuse, funcionamos desde o início com assembleias populares cotidianas, onde cada pessoa participa igualmente. Organizamos os bloqueios da cidade, das estações de serviço e as barrages filtrants. Na sequência, construímos uma barraca na praça central. Nós nos encontramos ali todos os dias para nos organizar, decidir as próximas ações, dialogar com as pessoas e receber aqueles que querem se juntar ao movimento. Nós organizamos também as 'sopas solidárias' para viver bons momentos juntos e nos conhecermos melhor. Em plena igualdade.

Mas agora o governo e algumas parcelas do movimento nos propõem nomear representantes por região! Ou seja, algumas pessoas que se tornarão os únicos 'interlocutores' dos poderes públicos e sintetizariam nossa diversidade.
Mas nós não queremos 'representantes' que acabarão, forçosamente, por falar em nosso lugar!

De que serviria? Em Commercy, uma delegação pontual se encontrou com o subprefeito, nas grandes cidades outras delegações encontraram diretamente o prefeito: elas já mostraram nossa cólera e nossa reivindicação. Eles já sabem que estamos determinados a pôr um fim nesse presidente odioso, este governo detestável e ao sistema podre que ambos encarnam.

[...]

Não é para melhor compreender nossa cólera e nossas reivindicações que o governo quer 'representantes': é para nos enquadrar e nos enterrar! Tal como acontece com a liderança dos sindicatos, ele procura intermediários, pessoas com quem ele possa negociar. Quem ele poderá pressionar para apaziguar a erupção. Pessoas que ele poderá em seguida cooptar e fazer dividir o movimento, para então enterrá-lo. Mas isso sem contar com a força e a inteligência de nosso movimento. Sem contar que estamos pensando, nos organizando, melhorando nossas ações que os deixam tão assustados, amplificando o movimento! E acima de tudo, sem levar em conta que há uma coisa muito importante, que em toda parte o movimento dos Coletes Amarelos reivindica sob diversas formas, muito além do poder de compra! Esta coisa é o poder ao povo, pelo povo e para o povo. É um sistema novo, onde 'aqueles que não são nada', como dizem com desprezo, retomam o poder sobre todos aqueles que se empanturram, sobre os dirigentes e os poderes do dinheiro. É a igualdade. É a justiça. É a liberdade. Eis o que nós queremos. E isto começa da base!

Se nomearmos 'representantes' e 'porta-vozes', acabaremos por nos tornar passivos. Pior: iremos reproduzir o sistema e funcionar de cima para baixo, como os crápulas que nos dirigem. Estes auto-proclamados 'representantes do povo' que enchem os bolsos, que fazem leis que apodrecem nossa vida e que servem aos interesses dos ultra-ricos!

Não coloquemos o dedo na engrenagem da representação e da cooptação. Não é o momento de confiar nossa palavra a um pequeno punhado, mesmo que eles pareçam honestos. Que nos escutem a todos, ou não escutem a ninguém!

A partir de Commercy, chamamos então a criação por toda a França de Comitês Populares, que funcionem em assembleias gerais regulares. Lugares onde a palavra se liberta, onde ousamos nos exprimir, se exercitar, se ajudar. Se é preciso que haja delegados, que seja ao nível de cada Comitê Popular local dos Coletes Amarelos, o mais perto da palavra do povo. 
Com mandatos imperativos, revogáveis e rotativos. Com transparência. Com confiança.

Chamamos também a que as centenas de grupos de coletes amarelos se dotem de uma barraca como a de Commercy, ou de uma 'casa do povo', como a de Saint-Nazare, enfim, de um lugar de encontro (un lieu de ralliement) e de organização! E que se coordenem entre si, ao nível local e departamental, em completa igualdade.

É assim que iremos ganhar, pois isso, lá no topo, eles não têm o hábito de administrar. E isso os deixa com muito medo.

Nós não nos deixaremos dirigir. Nós não nos deixaremos dividir, nem cooptar.

Não aos representantes e aos porta-vozes autoproclamados! Retomemos o poder sobre nossas vidas! Viva os coletes amarelos em sua diversidade! VIVA O PODER AO POVO, PELO POVO, PARA O POVO! ${ }^{21}$

Podemos compreender, a partir deste chamado, o quão profundamente democráticos são os anseios dos gilets jaunes. Não se trata de desconfiar da representação, mas de rejeitá-la enquanto instrumento por meio do qual "uma minoria se arroga o direito de falar e de agir no lugar da maioria" (Dardot; Laval, 2018, online), ainda que delegados próximos e submetidos às decisões das assembleias sejam reconhecidos como importantes e, por vezes, necessários. Neste sentido, a ideologia dos gilets jaunes encontra-se em sua prática: a rejeição de vanguardas intelectuais e a abertura para uma democracia múltipla e horizontal (Graeber, 2018).

Nada está dado ainda: "nada garante que
as possibilidades abertas por essa democracia
em ação se realizarão" (Dardot; Laval, 2018,
transformando esta espontaneidade em organi-
zação, como o exemplo de Commercy mostra
que é possível ser feito. Negri (2018) coloca a
formada em uma organização, a multidão é
neutralizada pelo sistema político, ela se torna
impotente. O mesmo é válido para sua redução
à direita, mas também à esquerda: é apenas em

sua independência que esta multidão pode funcionar" (Negri, 2018 - itálico no original, online). A multidão autônoma pode funcionar como um contra-poder capaz de forçar o "governo do capital" a conceder "novos espaços e fundos para o bem-estar da sociedade" (Negri, 2018, online). O primeiro sinal dessa manifestação do movimento como um contra-poder é que ele está dizendo "não" e demonstrando, na prática, a impossibilidade de reduzir sua multiplicidade multitudinária ao "um", a uma "unidade soberana" de um mecanismo representativo (Negri, 2019, online).

\section{CONSIDERAÇÕES FINAIS}

Uma das respostas aos movimentos de 2011 e às revoltas do precariado é o populismo de extrema direita, que toma diferentes formas, a depender do contexto: Donald Trump, Marine Le Pen, Brexit, Viktor Órban, Jair Bolsonaro, Rodrigo Duterte, o que atravessa todas essas manifestações é uma recusa à integração global e ao pluralismo interno, um retorno à nação, marcado por forte xenofobia. As forças da ordem estão apresentando sua resposta à crise do neoliberalismo, tentando instrumentalizar os movimentos da multidão para garantir sua permanência no poder. O futuro permanece incerto. O que sabemos, porém, é que a democracia representativa e seus ideais e instituições liberais não passaram incólume pela crise generalizada que vivemos neste início de século XXI.

A realidade contemporânea interpela as bases da democracia liberal, de seus valores e instituições, não apenas no debate público, mas também no interior da ciência política. O recrudescimento da xenofobia e das práticas explícitas de opressão étnica, racial, de gênero e de sexualidade desafia o suposto pluralismo e diversidade das sociedades ditas liberais. O emaranhado de dispositivos de repressão e controle e sua onipresença na vida cotidiana a fim de garantir uma suposta segurança desa- 
fiam o discurso da livre manifestação e das liberdades individuais. A ordem é o valor máximo. Os movimentos multitudinários que ocuparam praças, ruas e redes, rejeitando as mediações institucionais tradicionais, desafiam a dinâmica representativa e o lugar reservado para as ditas "pessoas comuns" no interior dos processos de decisão.

Colocam em cheque, assim, a cisão entre governantes e governados, representantes e representados, elites e povo e desmontam, de um só golpe, os pressupostos epistemológicos básicos de grande parte das teorias democráticas tradicionais, de que a unidade última de análise deveria ser o indivíduo auto-interessado e racional, maximizador de bem-estar material - isto é, as bases do individualismo metodológico. O edifício teórico e prático que sustentou a hegemonia da democracia liberal representativa encontra-se rachado por todos os lados. Resta saber o que iremos fazer com ele. Se o colocaremos abaixo, a fim de construir novas e melhores instituições. Ou se tentaremos remendá-lo, recuperando um status quo prévio ao neoliberalismo desenfreado. As demandas dos gilets jaunes não devem se dirigir a Macron, à classe política, nem mesmo ao governo representativo; elas devem se dirigir a si mesmo. A multidão precisa se afirmar como sujeito político. Ela não quer - e não precisa - de intermediação. A multidão deve ser seu próprio governo.

Recebido para publicação em 26 de março de 2019 Aceito em 10 de setembro de 2020
National Interest, $\mathrm{n}^{\mathrm{o}} 16$, publicado por Center for the National Interest, Washington D.C., pp. 3-18, 1989.

GAGO, Verónica.; MEZZADRA, Sandro. "Para una crítica de las operaciones extractivas del capital. Patrón de acumulación y luchas sociales en el tiempo de la financiarización”. In: Nueva Sociedad, n. 255, p. 38-52, Buenos Aires, enero-febrero de 2015.

GRAEBER, David. "The 'Yellow Vests' show how much the ground moves under our feet". Disponível em.: http:// criticallegalthinking.com/2018/12/09/the-yellow-vestsshow-how-much-the-ground-moves-under-our-feet/. 09 de dezembro de 2018. Acesso em 14 de janeiro de 2019.

HARDT, Michael.; NEGRI, Antonio. Assembly. A organização multitudinária do comum. São Paulo: Editora filosófica Politeia, 2018

HUNTINGTON, Samuel. "The Democratic Distemper”. In: The American Commonwealth. New York: Basic Books, pp. 9-38, 1976.

KLEIN, Naomi. Doutrina do Choque. Tradução Vania Cury. Rio de Janeiro: Nova Fronteira, 2008 [2007]

KURLANSKY, Mark. 1968. O ano que abalou o mundo. Trad. Sônia Coutinho. Rio de Janeiro: José Olympio, 2005.

LÖWY, Michael. A Evolução Política de Lukács: 1909-1929. Tradução de Heloísa Helena Mello e Agostinho Ferreira Martins. São Paulo: Cortez Editora, 1998 [1979]

MOUFFE, Chantal. For a Left Populism. Londres: Verso, 2018 (versão ebook sem paginação)

NEGRI, Antonio. "French Insurrection". Disponível em: https://www.versobooks.com/blogs/4158-frenchinsurrection. 08 de dezembro de 2018. Acesso em 25 de setembro de 2020 .

NEGRI, Antonio. "Reflections on the seventh round of the Gilets Jaunes". Disponível em: http://www.euronomade. info/? $p=11480$. 05 de janeiro de 2019. Acesso em 25 de setembro de 2020 .

ONFRAY, Michel. Gilet jaune \& Bonnet rouge. Disponível em: https://michelonfray.com/interventionshebdomadaires/gilet-jaune-bonnet-rouge. 2018. Acesso em 25 de setembro de 2020

PINHEIRO-MACHADO, Rosana. "França está reeditando os protestos de 2013 do Brasil”. Disponível em: https:// theintercept.com/2018/12/03/franca-protestos-2013brasil/. 04 de dezembro de 2018. Acesso em 25 de setembro de 2020.

TIBLE, Jean. "Brechas que inspiram: 1968 e nós”. Revista Outubro, n. 30, maio de 2018

WALLERSTEIN, Immanuel. 1968: Revolution in the World System. Theory and Society, XVIII, n. 4, p. 431-449, jul. 1989.

\section{REFERÊNCIAS}

BADIOU, Alain. A Hipótese Comunista. São Paulo: Boitempo Editorial, 2012 [2009]

BROWN, Wendy. Undoing the demos: neoliberalism's stealth revolution. New York: Zone Books, 2015

DARDOT, Pierre; LAVAL, Christian. "Com os Gilets Jaunes: contra a representação, pela democracia”. Disponível em https://passapalavra.info/2018/12/124182/, 13 de dezembro de 2018. Acesso em: 25 de setembro de 2020

FUKUYAMA, Francis. "The End of History?". In: The 
1968 AND US: crisis of representation and social movements

\section{Gabriel Pietro Siracusa}

This article examines the movement known as "yellow jackets", occurred in France, considering its main developments and demands until January 2019. The argument is first developed through a theoretical discussion about the crisis of representative democracy, intending to connect the movement that began in 2018 to those that occurred 50 years ago, in May 1968. In this regard, I searched to establish a line of continuity between those movements that demand a real democratization of power. In second place, the article highlights some possible contributions from the yellow jackets movement to a more open and plural conception of democracy and political science.

KEywords: Representative Democracy. Social Movements. Yellow Jackets. Multitude. Populist Moment.

\section{ET NOUS: la crise de représentation et les mouvements sociaux}

\section{Gabriel Pietro Siracusa}

L'article examine les principaux développements et demandes du mouvement connu sous le nom de « Gilets Jaunes », apparu en France, jusqu'au Janvier 2019. L'argument est développé premièrement par une discussion théorique sur la crise de la démocratie représentative en reliant le mouvement commencé en 2018 avec lesquels qui se sont passés il y a 50 années, en mai 1968. À cet égard, on cherche établir une ligne de continuité entre ces mouvements qui demandent une réelle démocratisation du pouvoir. Ensuite, l'article souligne quelques possibles contributions des Gilets Jaunes à une conception plus ouvert et pluriel de démocratie et de science politique.

Mots-CLÉs: Démocratie Représentative. Mouvements Sociaux. Gilets Jaunes. Multitude. Moment Populiste.

Gabriel Siracusa - Doutorando em Ciência Política pela Universidade de São Paulo. Mestre em Ciência Política pela Universidade de São Paulo. Formado em Relações Internacionais pela Universidade de São Paulo. Interesse em áreas diversas como: Economia Política Internacional, Teoria Política, Teoria das Relações Internacionais, Políticas Públicas, Filosofia. 